\title{
Postoperative acute kidney injury requiring continuous renal replacement therapy and outcomes after coronary artery bypass grafting: a nationwide cohort study
}

Tak Kyu Oh and In-Ae Song*

\begin{abstract}
Background: Previous studies reported that patients with acute kidney injury (AKI) requiring continuous renal replacement therapy (CRRT) after cardiac surgery were at a higher risk of postoperative mortality. However, the impact of AKI and CRRT on long-term mortality has not yet been identified. Therefore, we investigated whether postoperative AKI requiring CRRT was associated with one-year all-cause mortality after coronary artery bypass grafting (CABG).
\end{abstract}

Methods: For this population-based cohort study, we analyzed data from the National Health Insurance Service database in South Korea. The cohort included all adult patients diagnosed with ischemic heart disease who underwent isolated CABG between January 2012 and December 2017.

Results: A total of 15,115 patients were included in the analysis, and 214 patients (1.4\%) required CRRT for AKI after CABG during hospitalization. They received CRRT at $3.1 \pm 8.5$ days after CABG, for $3.1 \pm 7.8$ days. On multivariable Cox regression, the risk of 1-year all-cause mortality in patients who underwent CRRT was 7.69-fold higher. Additionally, on multivariable Cox regression, the 30-day and 90-day mortality after CABG in patients who underwent CRRT were 18.20-fold and 20.21-fold higher than the normal value, respectively. Newly diagnosed chronic kidney disease (CKD) requiring renal replacement therapy (RRT) 1 year after CABG in patients who underwent CRRT was 2.50-fold higher. In the generalized log-linear Poisson model, the length of hospital stay (LOS) in patients who underwent CRRT was 5\% longer.

Conclusions: This population-based cohort study showed that postoperative AKI requiring CRRT was associated with a higher 1-year all-cause mortality after CABG. Furthermore, it was associated with a higher rate of 30-day and 90-day mortality, longer LOS, and higher rate of CKD requiring RRT 1 year after CABG. Our results suggest that CRRTassociated AKI after CABG may be associated with an increased risk of mortality; hence, there should be interventions in these patients after hospital discharge.

Keywords: Acute kidney injury, Cardiovascular, CRRT, Coronary artery bypass grafting

\section{Background}

Acute kidney injury (AKI), defined as the rapid dete-

*Correspondence: songoficu@outlook.kr

Department of Anesthesiology and Pain Medicine, Seoul National University Bundang Hospital, 166 Gumi-ro, Bundang-gu, Seongnam 463-707, Korea rioration of kidney function, occurs in $2 \%-18 \%$ of all hospitalized patients [1-3]. Approximately $40 \%$ of total AKI cases among inpatients occur after surgical original author(s) and the source, provide a link to the Creative Commons licence, and indicate if changes were made. The images or other third party material in this article are included in the article's Creative Commons licence, unless indicated otherwise in a credit line to the material. If material is not included in the article's Creative Commons licence and your intended use is not permitted by statutory regulation or exceeds the permitted use, you will need to obtain permission directly from the copyright holder. To view a copy of this licence, visit http://creativecommons.org/licenses/by/4.0/. The Creative Commons Public Domain Dedication waiver (http://creativecommons.org/publicdomain/zero/1.0/) applies to the data made available in this article, unless otherwise stated in a credit line to the data. 
procedures [4]. AKI can delay recovery and increase hospital mortality and costs $[5,6]$. Postoperative AKI is more common after cardiac surgery than other types of surgery [7], with an incidence of up to 30\% [8]. Since the occurrence of AKI after cardiac surgery is associated with poorer long-term survival [9], the management of postoperative AKI has been an important issue and is considered a major clinical challenge in the management of patients undergoing cardiac surgery [10, 11 .

Continuous renal replacement therapy (CRRT) has been used to treat patients with severe AKI $[12,13]$. The incidence of AKI requiring CRRT after cardiac surgery is reported to be $1.0 \%-2.0 \%[14,15]$, and patients with severe AKI requiring CRRT are reported to have higher postoperative mortality $[15,16]$. A previous study reported in-hospital mortality as high as $43.5 \%$ in patients who required CRRT after cardiac surgery [17]. However, the relationship between relative longterm survival and postoperative AKI requiring CRRT has not been definitively identified, and further studies are needed. Additionally, the association between postoperative AKI requiring CRRT and various outcomes such as 30-day mortality, 90-day mortality, length of hospital stay (LOS), and newly diagnosed chronic kidney disease (CKD) requiring renal replacement therapy (RRT) after cardiac surgery has not been investigated in detail.

Therefore, this study aimed to investigate whether postoperative AKI requiring CRRT was associated with 1-year all-cause mortality after coronary artery bypass grafting (CABG), which is one of the most common cardiac surgical procedures [18]. Additionally, we investigated whether postoperative AKI requiring CRRT was associated with various negative outcomes after CABG.

\section{Methods}

\section{Design and ethical statements}

This population-based cohort study was conducted according to the Strengthening of Reporting of Observational Studies in Epidemiology guidelines and Population-Exposure-Comparator-Outcome (PECO) guidelines $[19,20]$. The study protocol was approved by the Institutional Review Board of Seoul National University Bundang Hospital (X-1908-556-901) and the Health Insurance Review and Assessment Service (NHIS-20191-505). This study was conducted in accordance with the guidelines of the Declaration of Helsinki. The requirement for informed consent was waived because the data analyses were performed retrospectively using anonymous data derived from the South Korean National Health Insurance Service (NHIS) database.

\section{Data source}

We used health records obtained from the NHIS database. In South Korea, all disease diagnoses and prescription information regarding drugs and/or procedures provided under the public insurance system should be registered with the NHIS database. The study data were extracted by an independent medical record technician at the NHIS center who had no conflicts of interest relevant to this study. Data extraction was performed on November 1, 2019.

\section{Study population}

We included all adult patients diagnosed with ischemic heart disease (International Classification of Diseases [ICD]-10 codes $\left.\mathrm{I} 20^{*}-\mathrm{I} 25^{*}\right)$ who underwent isolated CABG between January 2012 and December 2017. We excluded patients who 1) underwent repeat CABG surgeries, 2) were under the age of 18 years (i.e., pediatric patients), 3) did not have complete medical records, and 4) had any history of RRT before CABG (i.e., hemodialysis or peritoneal dialysis).

\section{Exposure: CRRT after CABG}

Patients who received CRRT for AKI during hospitalization after CABG were classified into the CRRT group. The remaining patients who did not undergo CRRT during hospitalization after CABG were classified into the control group.

\section{Study endpoints (outcomes)}

The primary endpoint of this study was 1-year all-cause mortality after CABG, which was defined as all-cause mortality occurring within 1 year of CABG. The secondary endpoints were 30-day and 90-day mortality after CABG, LOS after CABG, and newly diagnosed $C K D$ requiring $R R T$ after $C A B G$, which was evaluated 1 year after the date of CABG.

\section{Confounders}

We used the following variables as confounders: 1) demographic variables (age and sex), 2) socioeconomic variables (residence at the time of CABG [capital city/ other metropolitan city/other area] and income level at the time of CABG [four groups in quartile ratio]), 3) the Charlson comorbidity index at the time of CABG, which was calculated using registered ICD-10 diagnostic codes (Additional file 1) from 1 year before CABG to the date of $C A B G ; 4)$ use of an intraoperative cardiopulmonary bypass pump (off-pump CABG /on-pump CABG); 5) the number of coronary artery grafts (1 or $\geq 2)$; 6) absolute hospital volume as the total number of hospital beds (four groups in quartile ratio: Q1 $\leq 904$, 
$905 \leq \mathrm{Q} 2 \leq 1119,1120 \leq \mathrm{Q} 3 \leq 2413$, and $2414 \leq \mathrm{Q} 4) ; 7$ ) emergency or urgent $C A B G$; and 7) the year in which CABG was performed.

\section{Statistical analyses}

The demographic, socioeconomic, and clinical information between the CRRT and control groups were compared using the $t$-test for continuous variables and the chi-square test for categorical variables. First, we performed univariate and multivariate Cox regression analyses to investigate the hazard of 1-year all-cause mortality after CABG. All covariates were included in the multivariate model for the adjustment. We then performed three multivariable Cox regression analyses with two secondary endpoints using the landmark method (30-day mortality and 90-day mortality). The duration from the date of CABG to the date of death or 30-day, 90-day, and 1-year were used as time, while death within 30-day, 90-day, and 1-year after CABG were set as events in the time-to-event analyses. The results of Cox regression analysis were presented as hazard ratios (HRs) with 95\% confidence intervals (CIs). Log-log plots were used to confirm that the central assumption of the Cox proportional hazard models was satisfied, and there was no multicollinearity with a variance inflation factor of $<2.0$. $\mathrm{C}$-statistics were used to investigate the predictive ability of the multivariable Cox regression model with respect to 1-year all-cause mortality, and the results were presented as C-index with $95 \% \mathrm{CI}$ [21].

We subsequently conducted a multivariable logistic regression analysis for newly diagnosed CKD requiring RRT one year after CABG. All covariates were included in the multivariable logistic regression models for adjustment, and the results are presented as odds ratios (ORs) with $95 \%$ CIs. We fitted a GLM with all covariates as another secondary endpoint of LOS. For the GLM, a Poisson distribution was assumed for the dependent variable (LOS), and the log-link function was used. The results of GLM are presented as exponentiated regression coefficients with 95\% CIs. All statistical analyses were performed using SAS (version 9.4; SAS Institute Inc., Cary, NC, USA) and R software (version 3.6.2; R Foundation for Statistical Computing, Vienna, Austria). Statistical significance was set at $P<0.05$.

\section{Results}

A total of 16,582 patients who underwent isolated CABG for the treatment of ischemic heart disease between January 2012 and December 2017 were initially screened. Among them, we excluded 270 patients who underwent repeat CABG surgery, 11 were younger than 18 years, 511 had incomplete medical records, and 675 patients who had any history of RRT before CABG. Finally, 15,115

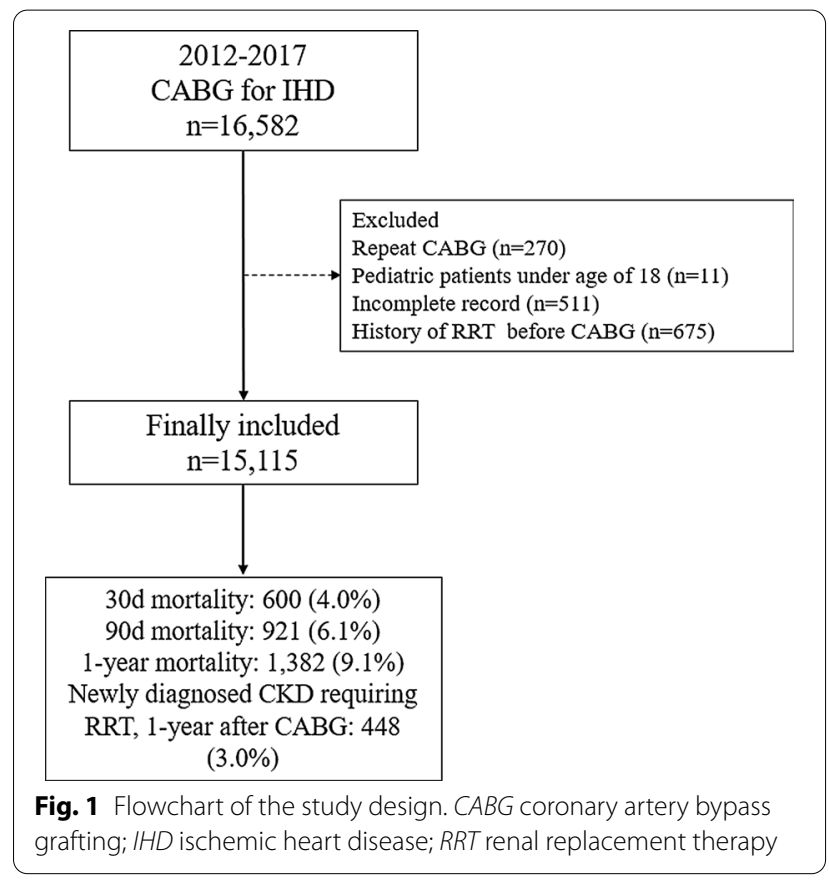

patients were included in the analysis (Fig. 1). Among them, 214 patients (1.4\%) underwent CRRT for AKI after CABG during hospitalization. They received CRRT at $3.1 \pm 8.5$ days after CABG for $3.1 \pm 7.8$ days during hospitalization. Among the 15,115 patients, 30-day, 90-day, and 1-year all-cause mortality after CABG occurred in $600(4.0 \%), 921(6.1 \%)$, and 1,382 (9.1\%) patients, respectively. Additionally, 448 (3.0\%) patients were diagnosed with CKD requiring RRT 1 year after CABG. Table 1 shows the results of the comparison of demographic, socioeconomic, and clinical information between the CRRT and control groups.

\section{One-year all-cause mortality after CABG}

Additional file 2 and Table 2 show the results of univariate and multivariate Cox regression analyses for 1-year all-cause mortality after CABG. In the multivariable model, the risk of 1-year all-cause mortality in patients who were exposed to CRRT was 7.69-fold higher (HR, 7.69; $95 \%$ CI: 6.54 to $9.05 ; P<0.001$ ) than that in the control group. The survival plot derived from the multivariable Cox regression model showed a similar tendency, as shown in Fig. 2. The C-index of the multivariable model was 0.83 ( $95 \%$ CI: 0.81 to 0.84 ).

\section{Analysis for secondary endpoints}

Table 3 shows the results of the multivariable models for the secondary endpoints. The 30-day and 90-day mortality rates after CABG in patients who underwent CRRT were 18.20-fold (HR: 18.20, 95\% CI: 13.01-24.71; 
Table 1 Comparision of the demographic, socioeconomic, and clinical information between CRRT group and control group

\begin{tabular}{|c|c|c|c|}
\hline Variable & CRRT $(n=214)$ & Control $(n=14,901)$ & $P$-value \\
\hline Age, year & $69.4(10.6)$ & $65.6(10.2)$ & $<0.001$ \\
\hline Sex, Male & $124(57.9)$ & $10,951(73.5)$ & $<0.001$ \\
\hline Residence at CABG & & & 0.768 \\
\hline Capital city & $45(21.0)$ & $3399(22.8)$ & \\
\hline Other metropolitan city & $38(17.8)$ & $2730(18.3)$ & \\
\hline Other area & $131(61.2)$ & $8772(58.9)$ & \\
\hline Income level at CABG & & & 0.073 \\
\hline Q1 & $42(19.6)$ & $2679(18.0)$ & \\
\hline Q2 & $52(24.3)$ & $3528(23.7)$ & \\
\hline Q3 & $32(15.0)$ & $3320(22.3)$ & \\
\hline Q4 & $88(41.1)$ & $5374(36.1)$ & \\
\hline Charlson comorbidity index at CABG & & & $<0.001$ \\
\hline $0-3$ & $23(10.7)$ & $3264(21.9)$ & \\
\hline $4-5$ & $59(27.6)$ & $4060(27.2)$ & \\
\hline$\geq 6$ & $132(61.7)$ & $7577(50.8)$ & \\
\hline Intraoperative CPB use & & & $<0.001$ \\
\hline Off Pump CABG & $43(20.1)$ & $8011(53.8)$ & \\
\hline On Pump CABG & $171(79.9)$ & $6890(46.2)$ & \\
\hline The number of coronary artery graft & & & $<0.001$ \\
\hline 1 & $51(23.8)$ & $2405(16.1)$ & \\
\hline$\geq 2$ & $163(76.2)$ & $12,496(83.9)$ & \\
\hline Total number of hospital bed & & & $<0.001$ \\
\hline $\mathrm{Q} 1 \leq 904$ & $65(30.4)$ & $3723(25.0)$ & \\
\hline $905 \leq \mathrm{Q} 2 \leq 1119$ & $70(32.7)$ & $3870(26.0)$ & \\
\hline $1120 \leq \mathrm{Q} 3 \leq 2413$ & $62(29.0)$ & $4547(30.5)$ & \\
\hline $2414 \leq \mathrm{Q} 4$ & $17(7.9)$ & $2761(18.5)$ & \\
\hline Length of hospital stay for CABG, day & $18.0(10.6)$ & $15.5(7.9)$ & $<0.001$ \\
\hline Newly diagnosis of CKD requiring RRT & $17(7.9)$ & $431(2.9)$ & $<0.001$ \\
\hline Urgent or Emergency CABG & $34(15.9)$ & $2464(16.5)$ & 0.800 \\
\hline The year of CABG & & & 0.883 \\
\hline 2012 & $31(14.5)$ & $2450(16.4)$ & \\
\hline 2013 & $29(13.6)$ & $2183(14.7)$ & \\
\hline 2014 & $37(17.3)$ & $2384(16.0)$ & \\
\hline 2015 & $41(19.2)$ & $2889(19.4)$ & \\
\hline 2016 & $45(21.0)$ & $3168(21.3)$ & \\
\hline 2017 & $31(14.5)$ & $1827(12.3)$ & \\
\hline
\end{tabular}

CABG coronary artery bypass grafting; CRRT continuous renal replacement therapy; $C P B$ cardiopulmonary bypass; $C K D$ chronic kidney disease; $R R T$ renal replacement therapy

$P<0.001$ ) and 20.21-fold (HR: 20.21, 95\% CI: $14.35-$ 29.20; $P<0.001$ ) higher than that of the control group, respectively. Newly diagnosed CKD requiring RRT, 1 year after CABG in patients who underwent CRRT was 2.50-old (OR: $2.50,95 \%$ CI: 1.49 to $4.19 ; P=0.001$ ) higher than that of the control group. The generalized linear regression model (GLM) for LOS showed that the LOS in patients who were exposed to CRRT was $5 \%$ longer (exponentiated regression coefficient: 1.05, 95\% CI: 1.02 to $1.08 ; P=0.004$ ) than that of the control group.

\section{Discussion}

This population-based cohort study in South Korea showed that patients who developed AKI requiring CRRT after CABG had higher 1-year all-cause mortality. Furthermore, these patients also had longer LOS, higher 30-day and 90-day mortality, and a higher incidence of newly diagnosed CKD requiring RRT 1 year after CABG. Our results suggest that CRRT-associated AKI after CABG is associated with an increased risk of longterm mortality and persistent kidney injury requiring 
Table 2 Mutlviariable Cox regression analysis for 1-year all-cause mortality after CABG

\begin{tabular}{|c|c|c|}
\hline Variable & $\begin{array}{l}\text { Multivariable model } \\
\text { HR }(95 \% \mathrm{Cl})\end{array}$ & $P$-value \\
\hline CRRT & $7.69(6.54,9.05)$ & $<0.001$ \\
\hline Age, year & $1.06(1.05,1.07)$ & $<0.001$ \\
\hline Sex, Male & $1.07(0.95,1.20)$ & 0.258 \\
\hline \multicolumn{3}{|l|}{ Residence at CABG } \\
\hline Capital city Capital city & 1 & \\
\hline Other metropolitan city & $1.00(0.85,1.19)$ & 0.977 \\
\hline Other area & $1.05(0.91,1.20)$ & 0.525 \\
\hline \multicolumn{3}{|l|}{ Economic status at CABG } \\
\hline Q1 & 1 & \\
\hline Q2 & $1.07(0.90,1.26)$ & 0.460 \\
\hline Q3 & $0.99(0.83,1.17)$ & 0.880 \\
\hline Q4 & $0.93(0.80,1.09)$ & 0.356 \\
\hline \multicolumn{3}{|l|}{ Total hospital bed number } \\
\hline $\mathrm{Q} 1 \leq 904$ & 1 & \\
\hline $905 \leq \mathrm{Q} 2 \leq 1119$ & $1.07(0.93,1.22)$ & 0.369 \\
\hline $1120 \leq Q 3 \leq 2413$ & $0.99(0.83,1.17)$ & 0.880 \\
\hline $2414 \leq \mathrm{Q} 4$ & $0.93(0.80,1.09)$ & 0.356 \\
\hline \multicolumn{3}{|c|}{ Charlson comorbidity index at CABG } \\
\hline $0-3$ & 1 & \\
\hline $4-5$ & $0.98(0.82,1.17)$ & 0.832 \\
\hline$\geq 6$ & $1.22(1.04,1.43)$ & 0.014 \\
\hline Urgent or Emergency CABG & $0.96(0.83,1.10)$ & 0.521 \\
\hline \multicolumn{3}{|l|}{ Intraoperative CPB use } \\
\hline Off Pump CABG & 1 & \\
\hline On Pump CABG & $1.95(1.73,2.19)$ & $<0.001$ \\
\hline \multicolumn{3}{|c|}{$\begin{array}{l}\text { The number of coronary artery graft } \\
\text { The number of coronary artery graft }\end{array}$} \\
\hline 1 & 1 & \\
\hline$\geq 2$ & $0.69(0.61,0.78)$ & $<0.001$ \\
\hline \multicolumn{3}{|l|}{ The year of CABG } \\
\hline 2012 & 1 & \\
\hline 2013 & $0.98(0.81,1.17)$ & 0.786 \\
\hline 2014 & $0.86(0.71,1.03)$ & 0.104 \\
\hline 2015 & $0.83(0.70,1.00)$ & 0.044 \\
\hline 2016 & $0.83(0.70,0.99)$ & 0.038 \\
\hline 2017 & $0.78(0.64,0.95)$ & 0.015 \\
\hline
\end{tabular}

C-index $0.83(0.81,0.84)$

$C A B G$ coronary artery bypass grafting; $H R$ hazard ratio; $C l$ confidence interval; $C R R T$ continuous renal replacement therapy; $C P B$ cardiopulmonary bypass; $C K D$ chronic kidney disease; $R R T$ renal replacement therapy

RRT. Although previous studies reported that patients with AKI requiring CRRT after cardiac surgery were at higher risk of postoperative mortality [15-17], its association with relative long-term outcomes such as 1-year mortality or persistent kidney injury requiring RRT at 1-year after CABG has not yet been reported. Therefore, our novel results suggest that severe postoperative AKI requiring CRRT might affect long-term outcomes (up to 1-year) after CABG.

For this study, we excluded patients with any history of RRT before CABG to focus on the effect of newly developed AKI requiring CRRT after CABG. In a retrospective cohort study by Pistolesi et al., severe postoperative AKI requiring CRRT was associated with higher 30-day and in-hospital mortality rates after cardiac surgery [22]. Another retrospective case-control study by PerezValdivieso et al. reported that severe postoperative AKI after cardiac surgery was associated with higher in-hospital mortality after CABG [23]. Other older studies have also stated that postoperative AKI requiring CRRT was an independent prognostic factor for higher mortality in patients undergoing cardiac surgery [15-17]. Our study revealed that a relatively long-term outcome (i.e., 1-year all-cause mortality) was negatively associated with AKI requiring CRRT after CABG. While the previous cohort studies analyzed relatively small sample sizes in a single institution [15-17, 22, 23], the sample size used in our study was very large, as we searched the entire national health database of South Korea.

Our finding regarding newly diagnosed CKD requiring RRT 1 year after CABG was the novel outcome of this study. Since the development of CKD is a well-known complication and sequelae among patients with AKI [24, 25], newly diagnosed CKD in these patients is an important clinical issue. A systemic review and meta-analysis of nine observational studies by Corredor et al. reported a higher long-term mortality risk in patients with persistent renal dysfunction compared to those in whom renal function recovers to baseline levels before discharge from the hospital [26]. Similarly, another cohort study by Swaminathan et al. reported that early recovery of renal function in patients who developed AKI after cardiac surgery was associated with improved long-term survival [27]. However, all these studies focused on the effect of postoperative AKI on long-term mortality after cardiac surgery, not on newly developed CKD requiring RRT after AKI. Considering that the cohort in our study had no history of RRT before CABG, our results suggest that AKI requiring CRRT after $C A B G$ was associated with a higher risk of developing end-stage renal disease after discharge from the hospital.

Our study has some limitations that should be addressed. First, we were unable to include some important physiological variables, such as body mass index at the time of CABG because they were not included in the NHIS database. Second, some important operative characteristics, such as the preoperative American Society of Anesthesiologists' physical status, duration of surgery, and anesthesia used for CABG, were not evaluated. Again, this was because these data were not 


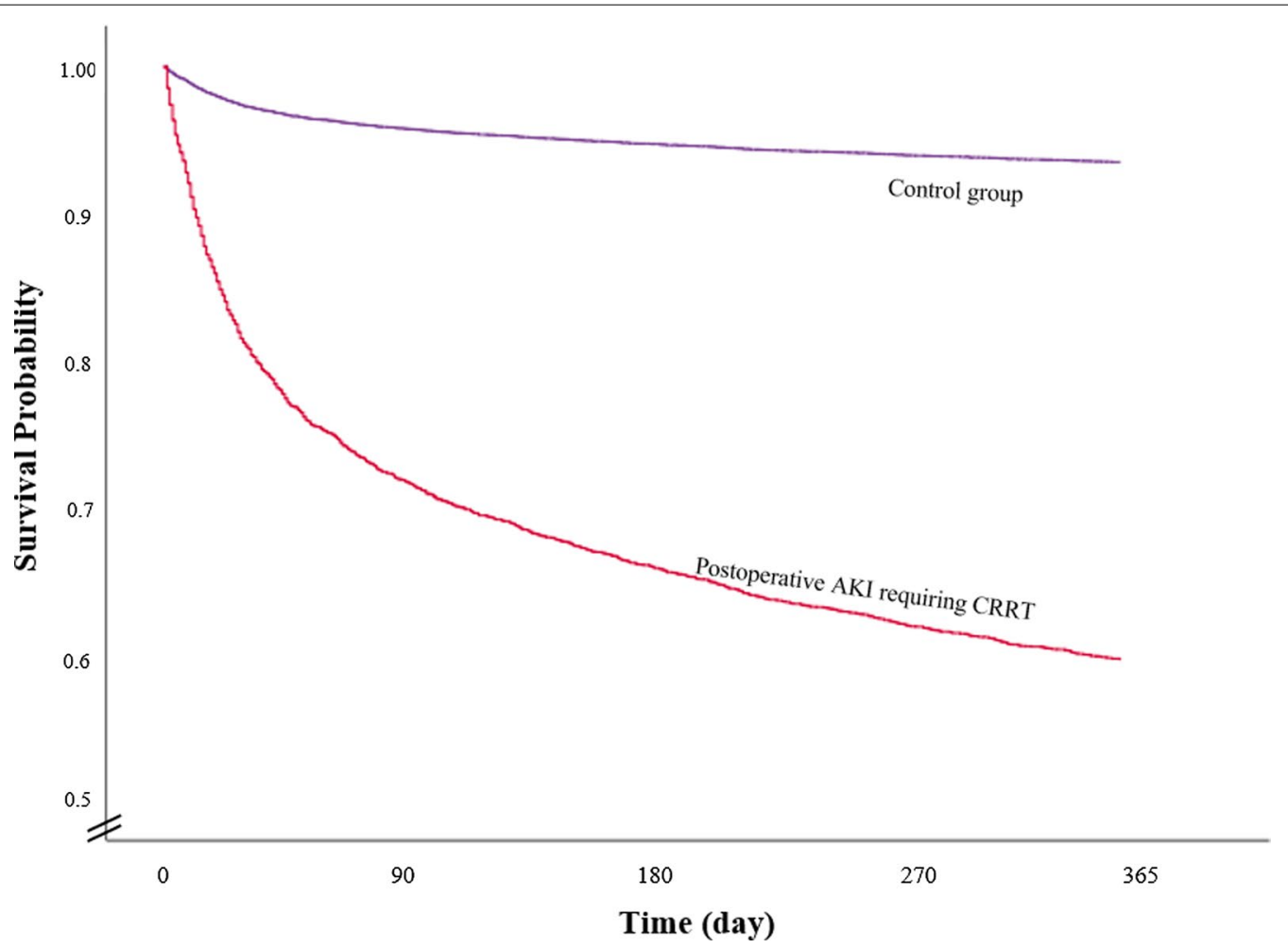

Fig. 2 Analysis of survival after isolated CABG. The plot of survival probability after CABG was derived from a multivariable Cox regression model. $C A B G$ coronary artery bypass grafting; $C R R T$ continuous renal replacement therapy

Table 3 Multivariable models for secondary endpoints

\begin{tabular}{lll}
\hline Variable & Multivariable model & $P$-value \\
& HR, OR or Exp.Coef $(95 \% \mathrm{Cl})$ &
\end{tabular}

\begin{tabular}{lll}
\hline $\begin{array}{l}\text { 30-day mortality after CABG } \\
\text { (HR) }\end{array}$ & & \\
$\quad$ CRRT & $18.20(13.01,24.71)$ & $<0.001$ \\
$\begin{array}{l}\text { 90-day mortality after CABG } \\
\text { (HR) }\end{array}$ & & \\
$\quad$ CRRT & & \\
Newly diagnosed CKD requir- & & \\
ing RRT, 1 year after CABG (OR) & & $<0.001$ \\
$\quad$ CRRT & $2.50(1.49,4.19)$ & 0.001 \\
LOS after CABG (Exp.Coef) & & \\
$\quad$ CRRT & $1.05(1.02,1.08)$ & 0.004 \\
\hline
\end{tabular}

$H R$ hazard ratio; OR odds ratio; Exp. Coef, exponentiated regression coefficient; $C l$ confidence interval; $C A B G$ coronary artery bypass grafting; $C R R T$ continuous renal replacement therapy; CKD chronic kidney disease; RRT renal replacement therapy; LOS length of hospital stay

included in the NHIS database. Third, we defined comorbidities using the ICD-10 codes registered in the NHIS database to calculate the Charlson comorbidity index, as shown in Additional file 1. However, these diseases registered according to the ICD-10 codes might have differed from the actual comorbidities present in the patients. Fourth, our adjustment for the multivariable analysis was controlled using only known confounders. Residual or unmeasured confounders may have affected the results of the analysis. Fifth, although we used the Charlson comorbidity index to reflect the comorbidity status at CABG, we were unable to evaluate other important comorbidity status parameters in detail. For example, we could not evaluate cardiac function in detail because this information was not included in the NHIS database. Lastly, patients requiring CRRT after CABG had AKI in this study. However, there might be non-renal causes of CRRT use after CABG. These include rhabdomyolysis or sepsis. Although sepsis or rhabdomyolysis was not a direct cause of CRRT, they could also result in the development of AKI, such as sepsis- [28] or rhabdomyolysisassociated AKI [29]. Therefore, AKI requiring CRRT after CABG may occur due to AKI, which is directly or indirectly associated with other pathologic conditions.

\section{Conclusion}

This population-based cohort study in South Korea showed that the development of postoperative AKI requiring CRRT was associated with higher 1-year all-cause mortality after CABG. Furthermore, it was 
associated with higher 30-day and 90-day mortality, longer LOS, and a higher rate of newly diagnosed CKD requiring RRT 1 year after CABG. Our results suggest that patients who undergo CRRT-associated AKI after CABG may be a high-risk group that needs intervention after hospital discharge.

\section{Abbreviations}

AKI: Acute kidney injury; CRRT: Continuous renal replacement therapy; CABG Coronary artery bypass grafting; CKD: Chronic kidney disease; LOS: Length of hospital stay; RRT: Renal replacement therapy; NHIS: National Health Insurance Service; ICD: International Classification of Diseases.

\section{Supplementary Information}

The online version contains supplementary material available at https://doi. org/10.1186/s13019-021-01704-7.

\section{Additional file 1. ICD-10 codes}

Additional file 2. Univariable Cox regression analysis for 1-year all-cause mortality after $C A B G$

\section{Acknowledgements}

None.

\section{Authors' contributions}

TKO and IAS contributed to the study design, analyzed the data, and drafted the first manuscript. TKO and IAS contributed to data acquisition and critically revised the manuscript. All authors read and approved the final version of the manuscript.

\section{Funding}

This research did not receive any specific grant from funding agencies in the public, commercial, or not-for-profit sectors.

\section{Availability of data and materials}

The data that support the findings of this study are available from the National Health Insurance System, but restrictions apply to the availability of these data, which were used under license for the current study and so are not publicly available. However, data are available from the authors upon reasonable request and with permission from the National Health Insurance System (https://nhiss.nhis.or.kr/bd/ab/bdaba000eng.do).

\section{Declarations}

\section{Ethics approval and consent to participate}

The study protocol was approved by the Institutional Review Board of Seoul National University Bundang Hospital (X-1908-556-901) and the Health Insurance Review and Assessment Service (NHIS-2019-1-505). This study was conducted in accordance with the guidelines of the Declaration of Helsinki. The requirement for informed consent was waived because the data analyses were performed retrospectively using anonymous data derived from the South Korean National Health Insurance Service (NHIS) database.

\section{Consent for publication}

Not applicable.

\section{Competing interests}

The authors declare that they have no competing interests.

Received: 28 December 2020 Accepted: 20 October 2021

Published online: 26 October 2021
References

1. Bellomo R, Kellum JA, Ronco C. Acute kidney injury. Lancet. 2012;380(9843):756-66.

2. Lewington AJ, Cerda J, Mehta RL. Raising awareness of acute kidney injury: a global perspective of a silent killer. Kidney Int. 2013;84(3):457-67.

3. Nash K, Hafeez A, Hou S. Hospital-acquired renal insufficiency. Am J Kidney Dis. 2002;39(5):930-6.

4. Thakar CV. Perioperative acute kidney injury. Adv Chronic Kidney Dis. 2013:20(1):67-75.

5. Palant CE, Amdur RL, Chawla LS. Long-term consequences of acute kidney injury in the perioperative setting. Curr Opin Anaesthesiol. 2017:30(1):100-4

6. Hobson C, Ozrazgat-Baslanti T, Kuxhausen A, Thottakkara P, Efron PA, Moore FA, et al. Cost and mortality associated with postoperative acute kidney injury. Ann Surg. 2015;261(6):1207-14.

7. Park JT. Postoperative acute kidney injury. Korean J Anesthesiol. 2017;70(3):258-66.

8. Rosner MH, Okusa MD. Acute kidney injury associated with cardiac surgery. Clin J Am Soc Nephrol. 2006;1(1):19-32.

9. Hansen MK, Gammelager H, Mikkelsen MM, Hjortdal VE, Layton JB, Johnsen SP, et al. Post-operative acute kidney injury and five-year risk of death, myocardial infarction, and stroke among elective cardiac surgical patients: a cohort study. Crit Care. 2013;17(6):R292.

10. Vives M, Hernandez A, Parramon F, Estanyol N, Pardina B, Munoz A, et al. Acute kidney injury after cardiac surgery: prevalence, impact and management challenges. Int J Nephrol Renovasc Dis. 2019;12:153-66.

11. Priyanka P, Zarbock A, Izawa J, Gleason TG, Renfurm RW, Kellum JA. The impact of acute kidney injury by serum creatinine or urine output criteria on major adverse kidney events in cardiac surgery patients. J Thorac Cardiovasc Surg 2020.

12. Ronco C, Ricci Z, De Backer D, Kellum JA, Taccone FS, Joannidis M, et al. Renal replacement therapy in acute kidney injury: controversy and consensus. Crit Care. 2015;19:146.

13. Uchino S, Bellomo R, Morimatsu H, Morgera S, Schetz M, Tan I, et al. Continuous renal replacement therapy: a worldwide practice survey. The beginning and ending supportive therapy for the kidney (B.E.S.T. kidney) investigators. Intensive Care Med 2007;33(9):1563-70.

14. Chertow GM, Lazarus JM, Christiansen CL, Cook EF, Hammermeister $\mathrm{KE}, \mathrm{Grover} \mathrm{F}$, et al. Preoperative renal risk stratification. Circulation. 1997:95(4):878-84.

15. Ostermann ME, Taube D, Morgan CJ, Evans TW. Acute renal failure following cardiopulmonary bypass: a changing picture. Intensive Care Med. 2000;26(5):565-71.

16. Bastin AJ, Ostermann M, Slack AJ, Diller GP, Finney SJ, Evans TW. Acute kidney injury after cardiac surgery according to risk/injury/failure/loss/ end-stage, acute kidney injury network, and kidney disease: improving global outcomes classifications. J Crit Care. 2013;28(4):389-96.

17. Lugones F, Chiotti G, Carrier M, Parent D, Thibodeau J, Ducharme B, et al. Continuous renal replacement therapy after cardiac surgery. Review of 85 cases. Blood Purif 2004;22(3):249-55.

18. Alexander JH, Smith PK. Coronary-artery bypass grafting. N Engl J Med. 2016;374(20):1954-64.

19. Vandenbroucke JP, von Elm E, Altman DG, Gotzsche PC, Mulrow CD, Pocock SJ, et al. Strengthening the Reporting of Observational Studies in Epidemiology (STROBE): explanation and elaboration. PLOS Med 2007;4(10):e297.

20. Morgan RL, Whaley $\mathrm{P}$, Thayer KA, Schunemann HJ. Identifying the PECO: A framework for formulating good questions to explore the association of environmental and other exposures with health outcomes. Environ Int. 2018;121(Pt 1):1027-31.

21. Pencina MJ, D'Agostino RB. Evaluating discrimination of risk prediction models: the C statistic. JAMA. 2015;314(10):1063-4.

22. Pistolesi V, Di Napoli A, Fiaccadori E, Zeppilli L, Polistena F, Sacco MI, et al. Severe acute kidney injury following cardiac surgery: short-term outcomes in patients undergoing continuous renal replacement therapy (CRRT). J Nephrol. 2016;29(2):229-39.

23. Perez-Valdivieso JR, Monedero P, Vives M, Garcia-Fernandez N, Bes-Rastrollo M, Gedrcc. Cardiac-surgery associated acute kidney injury requiring renal replacement therapy. A Spanish retrospective case-cohort study. BMC Nephrol 2009;10:27. 
24. Bucaloiu ID, Kirchner HL, Norfolk ER, Hartle JE 2nd, Perkins RM. Increased risk of death and de novo chronic kidney disease following reversible acute kidney injury. Kidney Int. 2012;81(5):477-85.

25. Coca SG, Singanamala S, Parikh CR. Chronic kidney disease after acute kidney injury: a systematic review and meta-analysis. Kidney Int. 2012;81(5):442-8.

26. Corredor C, Thomson R, Al-Subaie N. Long-term consequences of acute kidney injury after cardiac surgery: a systematic review and meta-analysis J Cardiothorac Vasc Anesth. 2016:30(1):69-75.

27. Swaminathan M, Hudson CC, Phillips-Bute BG, Patel UD, Mathew JP, Newman MF, et al. Impact of early renal recovery on survival after cardiac surgery-associated acute kidney injury. Ann Thorac Surg. 2010;89(4):1098-104.
28. Poston JT, Koyner JL. Sepsis associated acute kidney injury. BMJ 2019;364:k4891.

29. Omar AS, Ewila H, Aboulnaga S, Tuli AK, Singh R. Rhabdomyolysis following cardiac surgery: a prospective, descriptive, single-center study. Biomed Res Int. 2016;2016:7497936.

\section{Publisher's Note}

Springer Nature remains neutral with regard to jurisdictional claims in published maps and institutional affiliations.
Ready to submit your research? Choose BMC and benefit from:

- fast, convenient online submission

- thorough peer review by experienced researchers in your field

- rapid publication on acceptance

- support for research data, including large and complex data types

- gold Open Access which fosters wider collaboration and increased citations

- maximum visibility for your research: over $100 \mathrm{M}$ website views per year

At BMC, research is always in progress.

Learn more biomedcentral.com/submissions 